\title{
Extending the Van Laar Model to Multicomponent Systems
}

\author{
Ding-Yu Peng*
}

\author{
Department of Chemical Engineering, University of Saskatchewan 57 Campus Drive, Saskatoon, Saskatchewan S7N \\ 5A9, Canada
}

\begin{abstract}
The original van Laar equation for representing the excess Gibbs free energies of liquid mixtures contains certain deficiencies that have prevented the equation from being applied to multicomponent systems. We have analyzed the temperature dependency of the energy parameter in modern cubic equations of state and modified the original van Laar equation with a view to extending the equation to multicomponent systems. It is found that the consideration of the temperature dependency of the energy parameter has lead to a modified van Laar equation involving additional terms. These extra terms serve to provide some physical significance that can be attached to the van Laar equation to allow it to unambiguously represent the behavior of the excess Gibbs free energy and activity coefficients of nonideal solutions. The final form of the modified van Laar equation for multicomponent mixtures involves two size parameters and an interaction parameter for each of the constituent binary pairs; the latter parameter replaces a term consisting of a combination of the two energy parameters and two size parameters for the components in a binary mixture. For mixtures involving only hydrocarbons the size parameters can be readily calculated from the critical properties by means of any of the cubic equations of state of the van der Waals type.
\end{abstract}

Keywords: Activity coefficient, multicomponent, van Laar equation, Peng-Robinson equation.

\section{INTRODUCTION}

Vapor-liquid equilibrium (VLE) calculations constitute an important part of the engineering calculations encountered in chemical engineering practices. The main objectives of these calculations are to determine the compositions of the equilibrating phases in the system in question and subsequently the thermophysical properties, such as the heat capacity, enthalpy, entropy, and density, of the coexisting fluids. There are two approaches to accomplishing these calculations. One is the equation-of-state approach in which a single equation of state is used to represent the behavior of both the liquid and the gas phases. The other approach involves the use of an equation of state to represent the behavior of the gas phase and an excess Gibbs energy model to represent the behavior of the liquid phase. Among the many excess Gibbs free energy models published in the open literature, only a few have found widespread usage. In particular, the Margules equation [1], the van Laar equation [2,3,4], the Wilson equation [5], the NRTL equation [6], and the UNIQUAC equation [7] are listed in the compilation published by DECHEMA [8] and these equations are essentially the mainstream models. Of all these models, the van Laar model is the only one that was originated from a combination of an empirical equation of state with the rigorous thermal equation of state.

The original expression proposed by van Laar to represent the excess Gibbs free energy contains two energy parameters and two size parameters that characterize the

*Address correspondence to this author at the Department of Chemical Engineering, University of Saskatchewan 57 Campus Drive, Saskatoon, Saskatchewan S7N 5A9, Canada; Tel: 1-306-966-4767;

Fax: 1-306-966-4777; E-mail: dyp913@mail.usask.ca components in a binary system. The corresponding expressions for the activity coefficients can be readily derived by mathematical manipulation. However, the original forms of the van Laar equations did not find wide use except in textbooks as an example of solution theory. One could suggest a couple of reasons for this unfortunate consequence. One is that the use of the van der Waals parameters did not lead to any quantitative agreement between the calculated activity coefficients and the experimentally measured values. The other reason is that the form of the original van Laar equation dictates that the excess Gibbs energies calculated according to this equation can never be negative. Involving only two empirical parameters that are determined by means of fitting the experimental data, the modern forms of the van Laar equations can be applied to systems that exhibit negative deviations from Raoult's law. Nevertheless, these empirically evaluated parameters not only have masked the physical significance that can be attached to the van Laar equations, but also have prevented the van Laar equations from representing the behavior of multicomponent systems.

While there have been a number of attempts, for examples, such as those made by White [9], Wohl [10], Black [11], and Chien and Null [12], to extend the original van Laar equations to multicomponent systems, none of these attempts could be considered satisfactory and truly representing an extension of the original van Laar equations. In this study, we have rectified the excess Gibbs free energy equation developed by van Laar and extended the reformulated equations to multicomponent systems.

\section{THE ORIGINAL VAN LAAR EQUATIONS}

In 1906 van Laar [2] postulated that the behavior of two pure liquids and that of the resulting mixture when these two pure liquids are mixed could be represented by the van der 
Waals equation. He then proposed a reversible thermodynamic path to represent the mixing process and manipulated the thermal equation of state to develop an expression for the heat of mixing. He used the conventional quadratic mixing rule for the energy parameter $a$ and the linear mixing rule for the size parameter $b$. The resulting equation has the form

$H^{E}=\frac{x_{1} x_{2} b_{1} b_{2}}{x_{1} b_{1}+x_{2} b_{2}}\left(\frac{\sqrt{a_{1}}}{b_{1}}-\frac{\sqrt{a_{2}}}{b_{2}}\right)^{2}$

Upon making further assumptions that the mixing process involves no volume change and that the entropy of mixing is identical to that of an ideal solution, van Laar concluded that the expression for the excess Gibbs free energy is identical to that for the heat of mixing. Thus, the original van Laar equation implies that the excess Gibbs free energy, the excess internal energy, and the excess Helmholtz free energy are all equal to the excess enthalpy. Once the expression for the excess Gibbs free energy is established, the corresponding expressions for the activity coefficients can be obtained by differentiation according to the principles of thermodynamics. Thus, the original van Laar equations for the activity coefficients of the components in a binary mixture are given by

$$
\ln \gamma_{1}=\frac{b_{1} b_{2}^{2} x_{2}^{2}}{R T\left(x_{1} b_{1}+x_{2} b_{2}\right)^{2}}\left(\frac{\sqrt{a_{1}}}{b_{1}}-\frac{\sqrt{a_{2}}}{b_{2}}\right)^{2}
$$

and

$$
\ln \gamma_{2}=\frac{b_{1}^{2} b_{2} x_{1}^{2}}{R T\left(x_{1} b_{1}+x_{2} b_{2}\right)^{2}}\left(\frac{\sqrt{a_{1}}}{b_{1}}-\frac{\sqrt{a_{2}}}{b_{2}}\right)^{2}
$$

The limitation of the above equations is obvious. The perfect square term in the right-hand members of these equations precludes their application to systems exhibiting negative deviations from Raoult's law. This term also erroneously implies that components with identical critical pressure would form an ideal solution. Van Laar, however, expressed the activity coefficients in terms of two dimensionless auxiliary variables $r$ and $\beta$ and wrote the following equations for the partial pressures of the components:

$$
\begin{aligned}
& p_{1}=p_{1}^{\circ} x_{1} \exp \left[\frac{\beta x_{2}^{2}}{\left(1+r x_{2}\right)^{2}}\right] \\
& p_{2}=p_{2}^{\circ} x_{2} \exp \left[\frac{\beta x_{1}^{2}}{(1+r)\left(1+r x_{2}\right)^{2}}\right]
\end{aligned}
$$

where

$r=\frac{b_{2}}{b_{1}}-1$

and

$$
\beta=\frac{\left(b_{2} \sqrt{a_{1}}-b_{1} \sqrt{a_{2}}\right)^{2}}{R T b_{1}^{3}}
$$

Equations (4) and (5) are essentially the basis for the Carlson-Colburn [13] forms of the van Laar equations for the excess Gibbs free energy and the logarithms of the activity coefficients:

$$
\begin{aligned}
& G^{E}=\frac{R T A B x_{1} x_{2}}{A x_{1}+B x_{2}} \\
& \ln \gamma_{1}=\frac{A}{\left(1+\frac{A x_{1}}{B x_{2}}\right)^{2}}
\end{aligned}
$$

and

$$
\ln \gamma_{2}=\frac{B}{\left(1+\frac{B x_{2}}{A x_{1}}\right)^{2}}
$$

It can be readily shown that the parameters $A$ and $B$ in the Carlson and Colburn [13] forms are related to the dimensionless variables $r$ and $\beta$ by the following equations:

$$
\begin{aligned}
& A=\frac{\beta}{(1+r)^{2}} \\
& B=\frac{\beta}{1+r}
\end{aligned}
$$

In spite of the success of the equations (8) to (10) in correlating the experimental data of binary systems by using only two empirical constants, these equations cannot be extended to multicomponent systems.

\section{REFORMULATION OF THE VAN LAAR EQUA- TIONS}

The perfect square term appearing in equation (1) was a direct result of van Laar's strict adherence to the van der Waals equation by treating the energy parameter $a$ as a constant. Had van Laar had access to any of the modern cubic equations of state, he would have considered the effect of temperature on this parameter and developed a model that would be applicable not only to systems exhibiting positive deviations from Raoult's law but also to systems exhibiting negative deviations.

Let us consider a generic two-parameter cubic equation of state of the form

$$
P=\frac{R T}{v-b}-\frac{a}{(v+u b)(v+w b)}
$$

where the $a$ and $b$ are, respectively, the temperaturedependent energy parameter and temperature-independent size parameter and the $u$ and $w$ in the denominator are constants.

Upon adopting the same mixing rules and procedure as those used by van Laar in the development of his equation for the excess Gibbs free energy, we have obtained the following equation for the excess Gibbs free energy for a binary system:

$$
\frac{G^{E}}{R T}=\frac{x_{1} x_{2} b_{1} b_{2}}{x_{1} b_{1}+x_{2} b_{2}} \cdot \varepsilon_{12}
$$

where 


$$
\begin{aligned}
& \varepsilon_{12}=\varepsilon_{21}=\frac{C}{R T}\left\{\left(\frac{\sqrt{a_{1}}}{b_{1}}-\frac{\sqrt{a_{2}}}{b_{2}}\right)^{2}-T \cdot\left[\left(\frac{a_{1}^{\prime}}{b_{1}^{2}}+\frac{a_{2}^{\prime}}{b_{2}^{2}}\right)-\frac{\sqrt{a_{1} a_{2}}}{b_{1} b_{2}}\left(\frac{a_{1}^{\prime}}{a_{1}}+\frac{a_{2}^{\prime}}{a_{2}}\right)\right]\right\} \\
& C=\frac{1}{u-w} \ln \left(\frac{1+u}{1+w}\right)
\end{aligned}
$$

and

$a_{i}^{\prime}=\frac{d a_{i}}{d T}$

It is clear that the value of $\varepsilon_{12}$ as represented by equation (15) cannot be categorically declared as either positive or negative or zero without completing the calculations term by term. Thus, the excess Gibbs free energy represented by equation (14) can be positive, negative, or zero depending on the relative magnitude of the terms enclosed in the parentheses. The physical significance of equation (14) is quite clear: whether a binary system is a positive deviation system or a negative deviation system is entirely defined by the sign of the interaction parameter while the magnitude of the deviation is a result of this parameter in combination with the volumetric effects of the components. To illustrate the characteristics of the values of $\varepsilon_{12}$, we have used the PRSV equation of state $[14,15]$ to calculate the values of $\varepsilon_{12}$ for several binary systems. The results are presented in Fig. (1). It can be seen that for some systems the calculated $\varepsilon_{12}$ values are positive and for some other systems the $\varepsilon_{12}$ values are negative. However, all $\varepsilon_{12}$ values appear to be linearly dependent on temperature and the calculated $\varepsilon_{12}$ values do not necessarily represent the best parameter values in the reformulated van Laar equation. Therefore, the $\varepsilon_{12}$ term will be taken as an adjustable interaction parameter to be deter-

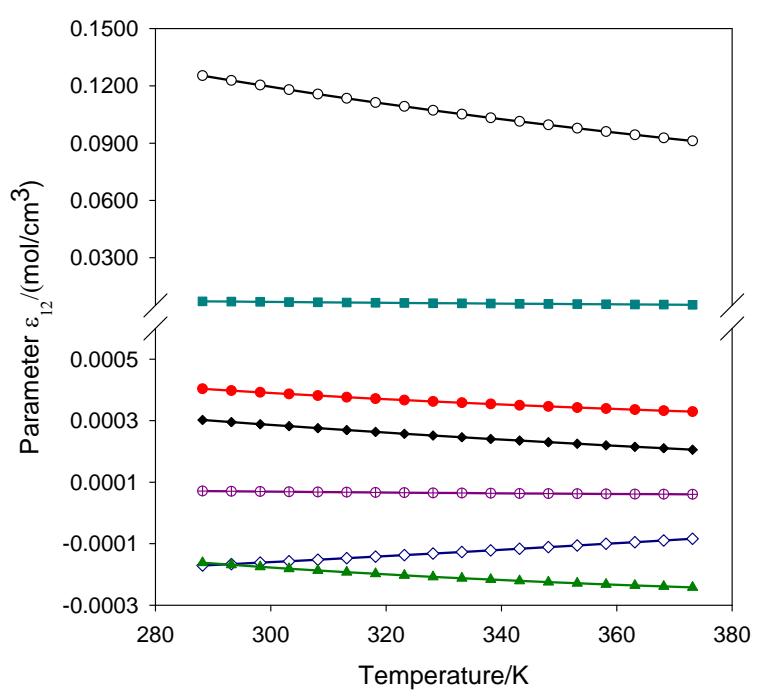

Fig. (1). Interaction parameters $\left(\varepsilon_{\mathrm{ij}}\right)$ calculated for selected binary mixtures by means of the PRSV equation of state: chloroform (1) + benzene (2) - - ; chloroform (1) + THF (2) - ; (1) + benzene (2)- - ; chloroform (1) + methyl acetate (2) $\checkmark$; benzene $(1)+$ methyl acetate (2) - ; $n$-butane $(1)+n$-heptane (2), — methanol (1) + water (2) - mined from the experimentally measured VLE values for the binary system of interest. This interaction parameter and the size parameters $b_{1}$ and $b_{2}$ constitute the three parameters required to represent a binary system in the application of the reformulated van Laar equations.

The excess Gibbs free energy equation for binary systems can be readily extended to multicomponent systems. The resulting excess Gibbs free energy equation and the corresponding equations for the logarithm of the activity coefficient of the $k$-th component in an $\mathrm{N}$-component system are

$$
\frac{G^{E}}{R T}=\frac{\sum_{i=1}^{N-1} \sum_{j=i+1}^{N} x_{i} x_{j} b_{i} b_{j} \varepsilon_{i j}}{\sum_{i=1}^{N} x_{i} b_{i}}
$$

and

$$
\ln \gamma_{k}=\frac{b_{k}}{\sum_{i=1}^{N} x_{i} b_{i}}\left(\sum_{\substack{i=1 \\ i \neq k}}^{N} x_{i} b_{i} \varepsilon_{i k}-\frac{G^{E}}{R T}\right)
$$

In particular, the equations for a ternary system are given by

$$
\begin{aligned}
& \frac{G^{E}}{R T}=\frac{x_{1} x_{2} b_{1} b_{2} \varepsilon_{12}+x_{2} x_{3} b_{2} b_{3} \varepsilon_{23}+x_{1} x_{3} b_{1} b_{3} \varepsilon_{13}}{x_{1} b_{1}+x_{2} b_{2}+x_{3} b_{3}} \\
& \ln \gamma_{1}=\frac{b_{1}}{x_{1} b_{1}+x_{2} b_{2}+x_{3} b_{3}}\left(x_{2} b_{2} \varepsilon_{12}+x_{3} b_{3} \varepsilon_{13}-\frac{G^{E}}{R T}\right) \\
& \ln \gamma_{2}=\frac{b_{2}}{x_{1} b_{1}+x_{2} b_{2}+x_{3} b_{3}}\left(x_{1} b_{1} \varepsilon_{12}+x_{3} b_{3} \varepsilon_{23}-\frac{G^{E}}{R T}\right)
\end{aligned}
$$

and

$$
\ln \gamma_{3}=\frac{b_{3}}{x_{1} b_{1}+x_{2} b_{2}+x_{3} b_{3}}\left(x_{1} b_{1} \varepsilon_{13}+x_{2} b_{2} \varepsilon_{23}-\frac{G^{E}}{R T}\right)
$$

\section{APPLICATION OF THE REFORMULATED VAN LAAR EQUATIONS}

We have found that the size parameters for hydrocarbons, which generally belong to the normal fluids, can be estimated from the critical constants by means of any of the cubic equations of state that conform to the generic cubic equation of state represented by equation (13). In this paper, all size parameters including those for the polar components were calculated by means of the Peng-Robinson equation of state [16] according to the equation

$b=\frac{0.077796 R T_{c}}{P_{c}}$

The critical constants along with the calculated size parameters for ten hydrocarbons and four non-hydrocarbons are presented in Table $\mathbf{1}$.

As the size parameters have units of $\mathrm{cm}^{3} \mathrm{~mol}^{-1}$, the inter-

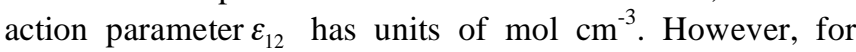
simplicity, all parameters may be taken to be dimensionless without affecting the calculated VLE results. It should be 
Table 1. Critical Constants and the Size Parameters Calculated by Means of Equation (24)

\begin{tabular}{|l|c|c|c|}
\hline \multicolumn{1}{|c|}{ Substance } & $\mathbf{T}_{\mathbf{c}} / \mathbf{K}$ & $\mathbf{P}_{\mathbf{c}} / \mathbf{k P a}$ & $\mathbf{b} /(\mathbf{c m} / \mathbf{m o l})$ \\
\hline \hline n-Pentane & 469.70 & 3369.02 & 90.175 \\
\hline n-Hexane & 507.30 & 3012.36 & 108.92 \\
\hline n-Heptane & 540.10 & 2735.75 & 127.69 \\
\hline n-Octane & 568.76 & 2486.49 & 147.95 \\
\hline Cyclohexane & 553.64 & 4075.00 & 87.875 \\
\hline Methylcyclohexane & 572.12 & 3471.00 & 106.61 \\
\hline Benzene & 562.16 & 4898.00 & 74.235 \\
\hline Toluene & 591.80 & 4106.00 & 93.223 \\
\hline Water & 647.29 & 22089.75 & 18.953 \\
\hline Methanol & 512.58 & 8095.79 & 40.952 \\
\hline Chloroform & 536.55 & 5472.00 & 63.421 \\
\hline Tetrahydrofuran & 540.10 & 5190.00 & 67.309 \\
\hline
\end{tabular}

Table 2. Correlation of Vapor-Liquid Equilibrium Data Measured under Isobaric Conditions

\begin{tabular}{|c|c|c|c|c|c|c|c|}
\hline Component 1 & Component 2 & $\mathbf{P} / \mathbf{k P a}$ & NP & $10^{2} \varepsilon_{12}$ & $\Delta T /{ }^{\circ} \mathrm{C}$ & $\Delta y$ & Reference \\
\hline$n$-Hexane & Benzene & 101.33 & 12 & 0.4732 & 0.11 & 0.0076 & [19] \\
\hline$n$-Heptane & Benzene & 24.0 & 9 & 0.6038 & 0.16 & 0.0043 & {$[20]$} \\
\hline$n$-Heptane & Benzene & 53.33 & 9 & 0.4962 & 0.11 & 0.0015 & [20] \\
\hline Cyclohexane & Benzene & 101.19 & 20 & 0.4534 & 0.10 & 0.0057 & {$[21]$} \\
\hline Cyclohexane & Benzene & 101.33 & 30 & 0.4283 & 0.07 & 0.0188 & {$[18]$} \\
\hline Cyclohexane & $n$-Hexane & 101.33 & 16 & 0.0265 & 0.07 & 0.0056 & [18] \\
\hline Cyclohexane & $n$-Heptane & 101.33 & 19 & -0.0013 & 0.08 & 0.0071 & [22] \\
\hline Cyclohexane & $n$-Heptane & 101.33 & 25 & 0.0294 & 0.07 & 0.0069 & [23] \\
\hline Methylcyclohexane & $n$-Heptane & 101.33 & 11 & 0.0059 & 0.04 & 0.0010 & {$[22]$} \\
\hline Methylcyclohexane & $n$-Heptane & 101.33 & 12 & 0.0125 & 0.02 & 0.0020 & {$[24]$} \\
\hline Benzene & Toluene & 101.33 & 12 & -0.0174 & 0.05 & 0.0046 & [19] \\
\hline$n$-Hexane & Toluene & 101.33 & 25 & 0.3158 & 0.41 & 0.0110 & {$[22]$} \\
\hline$n$-Heptane & Toluene & 101.33 & 22 & 0.2346 & 0.23 & 0.0048 & [22] \\
\hline$n$-Heptane & Toluene & 101.33 & 17 & 0.2623 & 0.04 & 0.0029 & [25] \\
\hline
\end{tabular}

noted that for a binary system, if necessary, the value of one of the size parameters can be arbitrarily set and the values of the other size parameter and the interaction parameter can then be determined by regression on the VLE data. This is so because the three parameters in the reformulated van Laar equation for a binary system are related to the coefficients in the Carlson and Colburn [13] forms by the following simultaneous equations:

$\frac{b_{1}}{b_{2}}=\frac{A}{B}$

$b_{1} \varepsilon_{12}=A$
The reformulated van Laar model was tested by correlating the VLE data of a number of hydrocarbon systems. The optimal values of the binary interaction parameters for all the binary systems were determined by means of Barker's method [17]. For each of the binary mixtures tested, the correlation of the VLE data was essentially a one-parameter regression process because the size parameters have already been calculated by means of Equation (24). The optimal interaction parameters determined from VLE data measured under isobaric conditions are presented in Table $\mathbf{2}$ whereas those determined from data measured under isothermal conditions are presented in Table 3. As shown in Figs. (2 to 19), the VLE values of the hydrocarbon systems as well as the 
Table 3. Correlation of Vapor-Liquid Equilibrium Data Measured under Isothermal Conditions

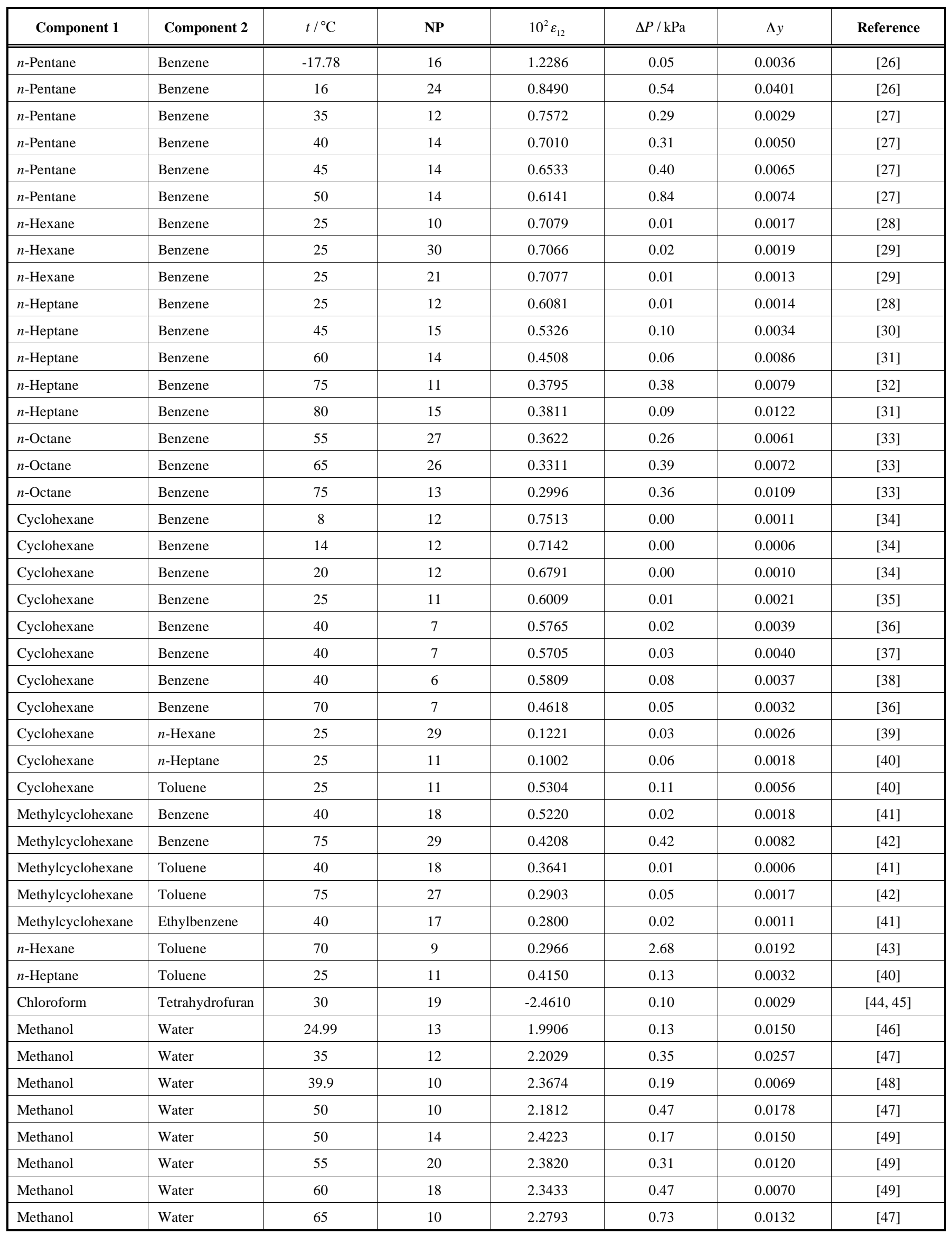




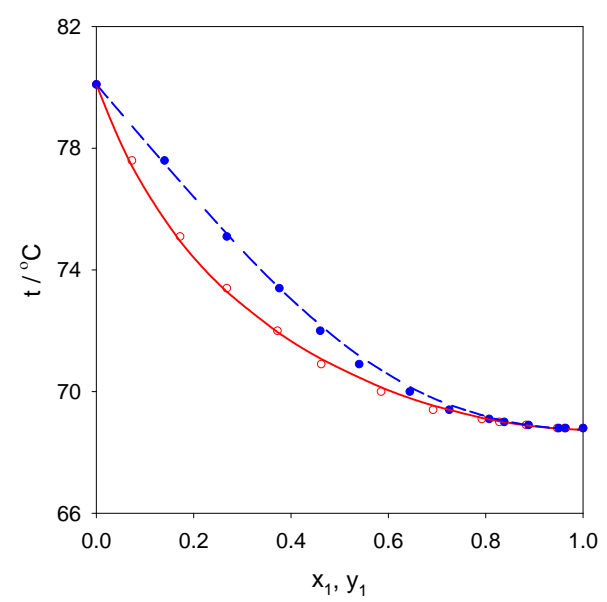

Fig. (2). Correlation of vapor-liquid equilibrium values for the $\{n$ hexane (1) + benzene (2)\} system at $101.33 \mathrm{kPa}$. Experimental mole fraction of component 1 in liquid $\mathrm{O}$; experimental mole fraction of component 1 in vapor - ; calculated mole fraction of component 1 in liquid — ; calculated mole fraction of component 1 in vapor - - - .

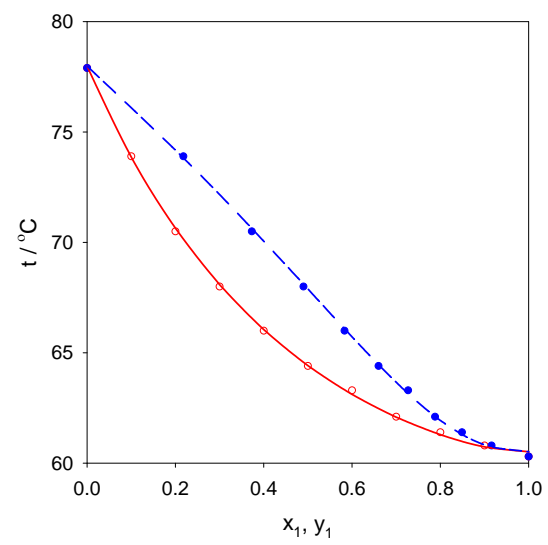

Fig. (3). Correlation of vapor-liquid equilibrium values for the $\{$ benzene $(1)+n$-heptane (2) $\}$ system at $53.33 \mathrm{kPa}$. Experimental mole fraction of component 1 in liquid $\mathrm{O}$; experimental mole fraction of component 1 in vapor $\boldsymbol{O}$; calculated mole fraction of component 1 in liquid — ; calculated mole fraction of component 1 in vapor - - - .

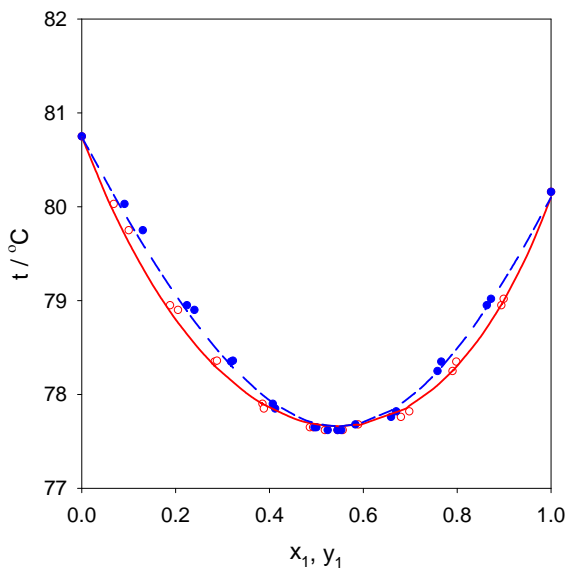

Fig. (4). Correlation of vapor-liquid equilibrium values for the \{benzene (1) + cyclohexane (2)\} system at $101.33 \mathrm{kPa}$. Experimental mole fraction of component 1 in liquid $O$; experimental mole fraction of component 1 in vapor $\mathbf{0}$; calculated mole fraction of component 1 in liquid — 1 in vapor - - - .

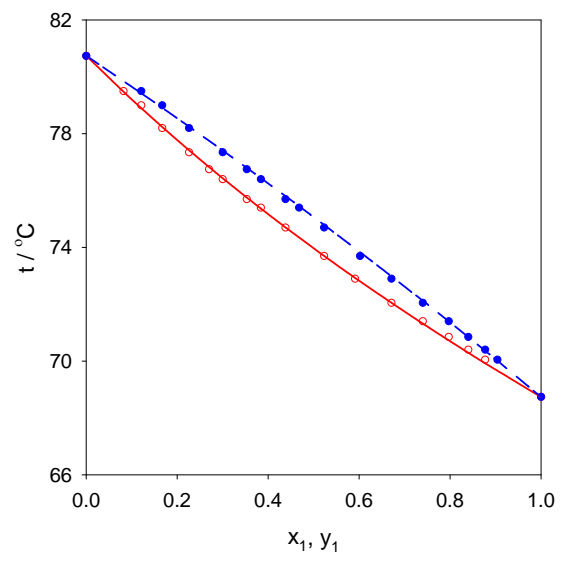

Fig. (5). Correlation of vapor-liquid equilibrium values for the $\{n$ hexane (1) + cyclohexane (2)\} system at $101.33 \mathrm{kPa}$. Experimental mole fraction of component 1 in liquid $O$; experimental mole fraction of component 1 in vapor $\mathbf{0}$; calculated mole fraction of component 1 in liquid _ $\_$calculated mole fraction of component 1 in vapor - - - .

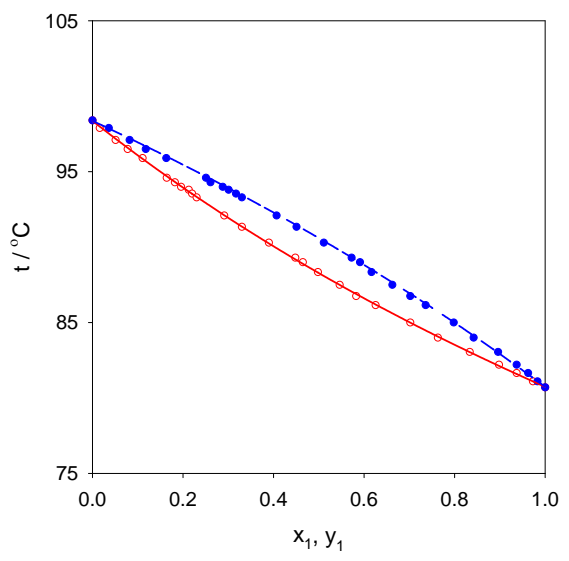

Fig. (6). Correlation of vapor-liquid equilibrium values for the $\{n$-hexane $(1)+n$-heptane (2) $\}$ system at $101.33 \mathrm{kPa}$. Experimental mole fraction of component 1 in liquid $O$; experimental mole fraction of component 1 in vapor - ; calculated mole fraction of component 1 in liquid _ _ calculated mole fraction of component 1 in vapor - - -

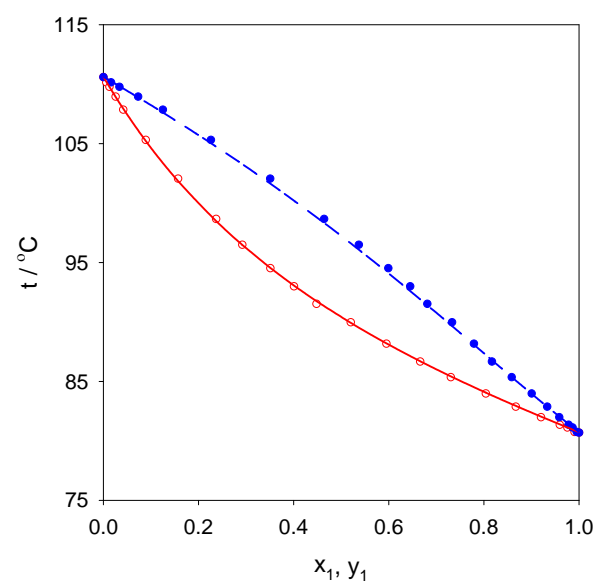

Fig. (7). Correlation of vapor-liquid equilibrium values for the \{cyclohexane (1) + toluene (2)\} system at $101.33 \mathrm{kPa}$. Experimental mole fraction of component 1 in liquid $O$; experimental mole fraction of component 1 in vapor $\boldsymbol{0}$; calculated mole fraction of component 1 in liquid — ; calculated mole fraction of component 1 in vapor - - - . 


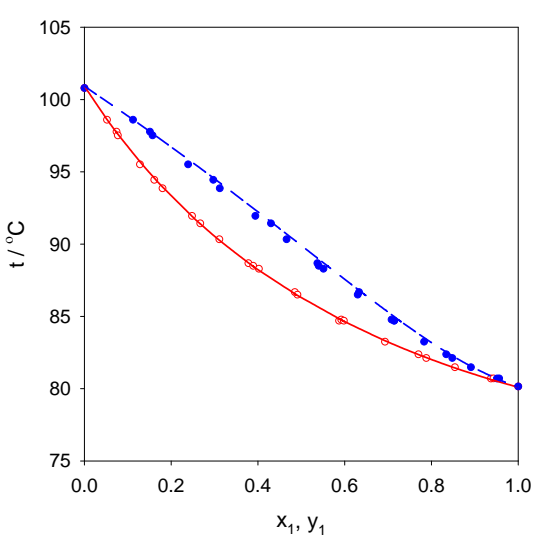

Fig. (8). Correlation of vapor-liquid equilibrium values for the \{benzene (1) + methylcyclohexane (2)\} system at $101.33 \mathrm{kPa}$. Experimental mole fraction of component 1 in liquid $O$; experimental mole fraction of component 1 in vapor 0 ; calculated mole fraction of component 1 in liquid — ; calculated mole fraction of component 1 in vapor - - - .

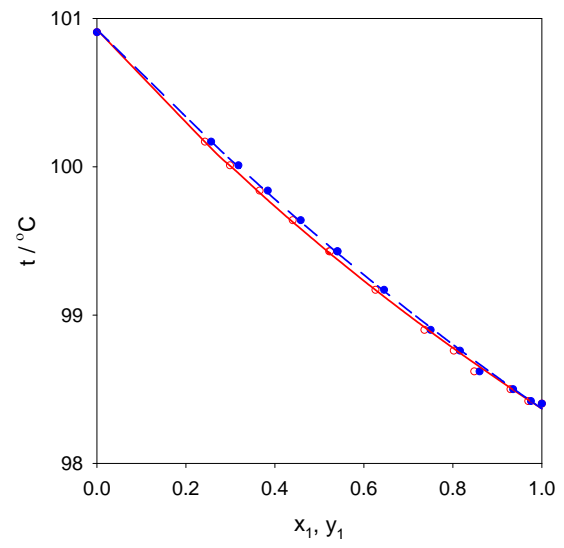

Fig. (9). Correlation of vapor-liquid equilibrium values for the $\{n$-heptane (1) + methylcyclohexane (2) $\}$ system at $101.33 \mathrm{kPa}$. Experimental mole fraction of component 1 in liquid $O$; experimental mole fraction of component 1 in vapor 0 ; calculated mole fraction of component 1 in liquid _ ; calculated mole fraction of component 1 in vapor - - - .

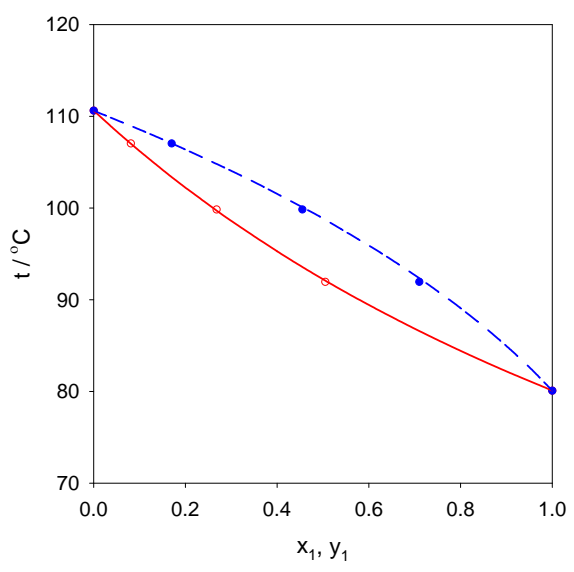

Fig. (10). Correlation of vapor-liquid equilibrium values for the \{benzene (1) + toluene (2)\} system at $101.33 \mathrm{kPa}$. Experimental mole fraction of component 1 in liquid $O$; experimental mole fraction of component 1 in vapor $\mathbf{0}$; calculated mole fraction of component 1 in liquid __ ; calculated mole fraction of component 1 in vapor - - - .

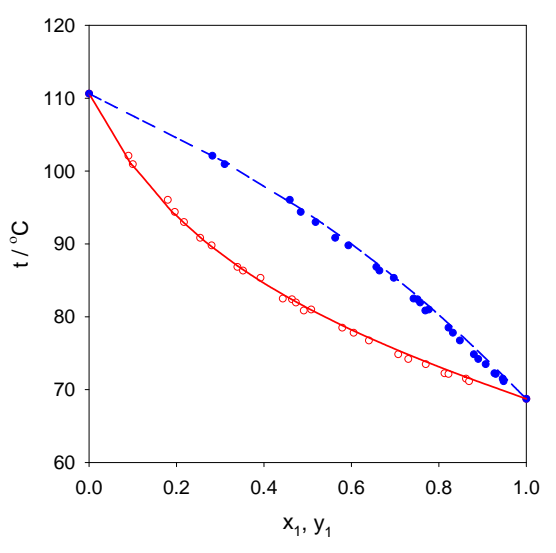

Fig. (11). Correlation of vapor-liquid equilibrium values for the $\{n$-hexane (1) + toluene (2) $\}$ system at $101.33 \mathrm{kPa}$. Experimental mole fraction of component 1 in liquid $O$; experimental mole fraction of component 1 in vapor - ; calculated mole fraction of component 1 in liquid _ ; calculated mole fraction of component 1 in vapor - - - .

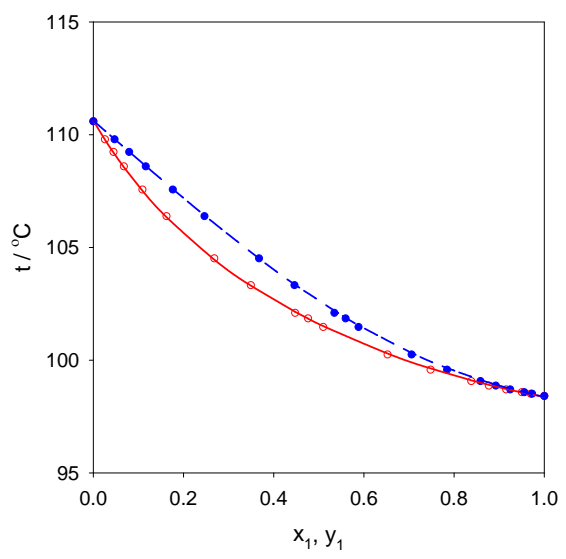

Fig. (12). Correlation of vapor-liquid equilibrium values for the $\{n$-heptane $(1)+$ toluene $(2)\}$ system at $101.33 \mathrm{kPa}$. Experimental mole fraction of component 1 in liquid $O$; experimental mole fraction of component 1 in vapor - calculated mole fraction of component 1 in liquid __ ; calculated mole fraction of component 1 in vapor - - .

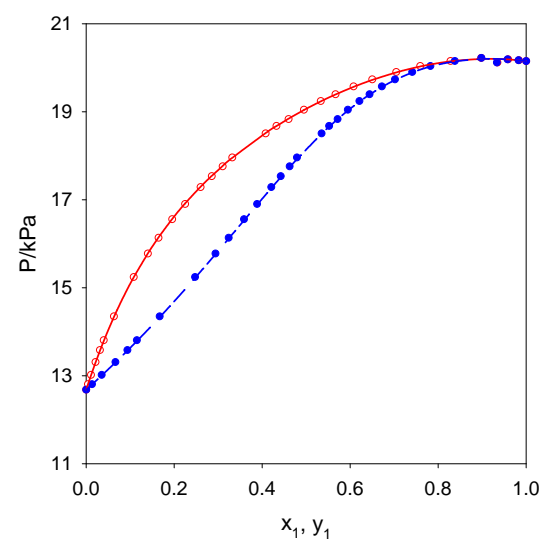

Fig. (13). Correlation of vapor-liquid equilibrium values for the $\{n$-hexane (1) + benzene (2) $\}$ system at $298.15 \mathrm{~K}$. Experimental mole fraction of component 1 in liquid $O$; experimental mole fraction of component 1 in vapor - calculated mole fraction of component 1 in liquid _ ; calculated mole fraction of component 1 in vapor - - . . 


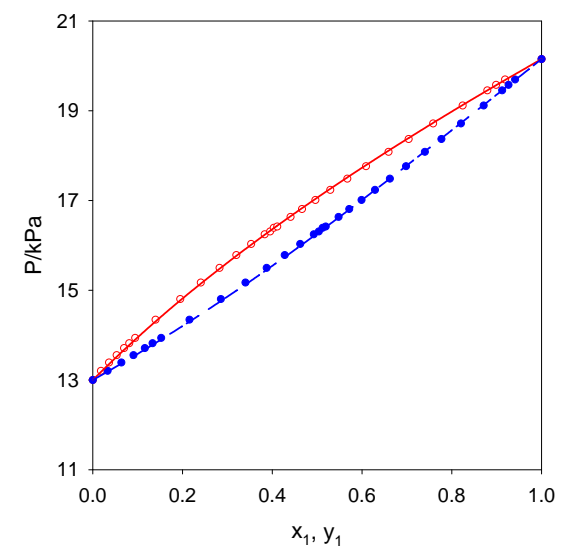

Fig. (14). Correlation of vapor-liquid equilibrium values for the $\{n$-hexane $(1)+$ cyclohexane (2) $\}$ system at $298.15 \mathrm{~K}$. Experimental mole fraction of component 1 in liquid $O$; experimental mole fraction of component 1 in vapor $\mathbf{0}$; calculated mole fraction of component 1 in liquid _ ; calculated mole fraction of component 1 in vapor - - - .

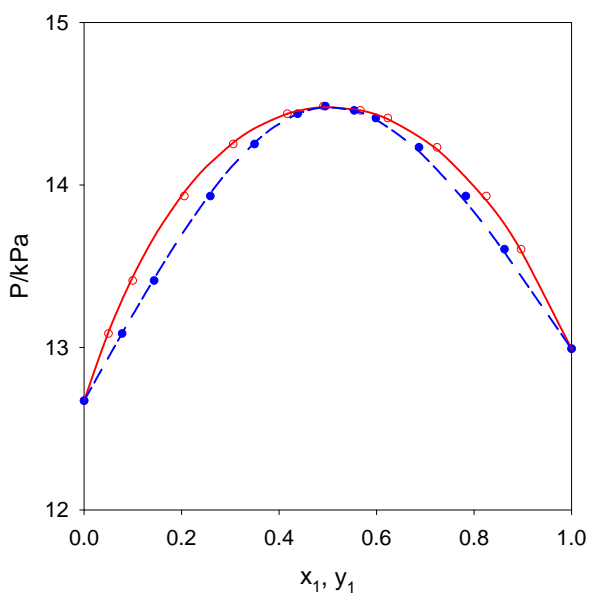

Fig. (15). Correlation of vapor-liquid equilibrium values for the \{cyclohexane (1) + benzene (2)\} system at 298.15 K. Experimental mole fraction of component 1 in liquid $O$; experimental mole fraction of component 1 in vapor ; calculated mole fraction of component 1 in liquid _ ; calculated mole fraction of component 1 in vapor - - - .

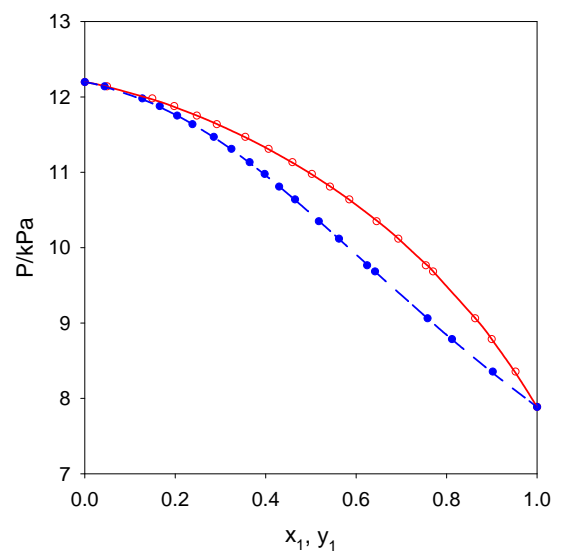

Fig. (16). Correlation of vapor-liquid equilibrium values for the $\{$ toluene (1) + methylcyclohexane (2)\} system at $313.15 \mathrm{~K}$. Experimental mole fraction of component 1 in liquid $O$; experimental mole fraction of component 1 in vapor 0 ; calculated mole fraction of component 1 in liquid _ ; calculated mole fraction of component 1 in vapor - - - .

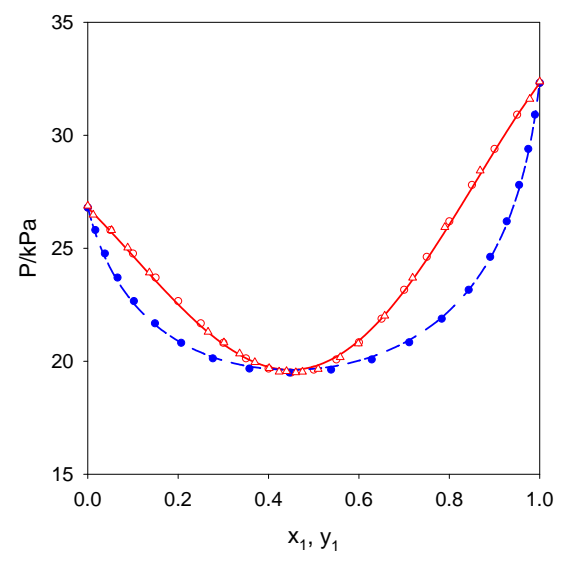

Fig. (17). Correlation of vapor-liquid equilibrium values for the \{chloroform (1) + THF (2)\} system at $303.15 \mathrm{~K}$. Experimental mole fraction of component 1 in liquid $O$; experimental mole fraction of component 1 in vapor 0 ; calculated mole fraction of component 1 in liquid _ ; calculated mole fraction of component 1 in vapor - - . .

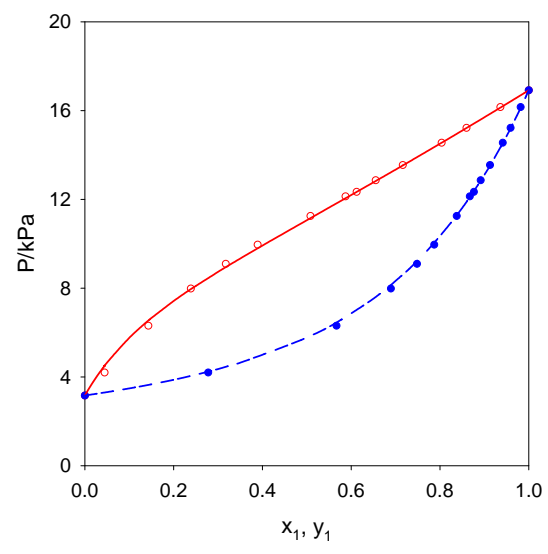

Fig. (18). Correlation of vapor-liquid equilibrium values for the \{methanol (1) + water (2)\} system at $298.15 \mathrm{~K}$. Experimental mole fraction of component 1 in liquid $O$; experimental mole fraction of component 1 in vapor 0 ; calculated mole fraction of component 1 in liquid — ; calculated mole fraction of component 1 in vapor - - - .

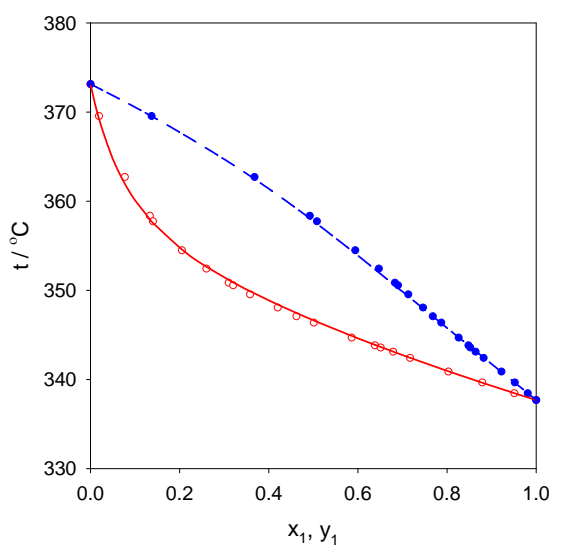

Fig. (19). Correlation of vapor-liquid equilibrium values for the \{methanol (1) + water (2)\} system at $101.33 \mathrm{kPa}$. Experimental mole fraction of component 1 in liquid $O$; experimental mole fraction of component 1 in vapor - ; calculated mole fraction of component 1 in liquid _ ; calculated mole fraction of component 1 in vapor - - - . 
two strongly polar non-hydrocarbon systems all can be accurately represented by the reformulated van Laar equations with constant size parameters.

For each of the benzene-alkane pairs, the interaction parameters appear to be linearly dependent on temperature; the value of $\varepsilon_{12}$ decreases as the temperature is increased. It is interesting to note that the two sets of data reported for the \{cyclohexane $+n$-heptane $\}$ system at $101.33 \mathrm{kPa}$ would characterize this mixture differently. The data obtained by Myers [23] can be represented by the reformulated van Laar equations with a positive interaction parameter. However, the data reported by Sieg [22] would characterize this mixture as a negative-deviation system because the interaction parameter determined from the data has a negative value. In practice, the $\{$ cyclohexane $+n$-heptane $\}$ system could be considered an ideal solution and the small values of the interaction parameter probably resulted from experimental errors. Similar reasoning may be used to explain the small negative value of the interaction parameter for the \{benzene + toluene\} system.

Although the size parameters generated by an equation of state are not necessarily suitable for polar fluids, some VLE values of non-hydrocarbon mixtures can be correlated by using the equation-of-state-based size parameters and a suitable interaction parameter. It is remarkable that the VLE data for the methanol-water system can be very well correlated by means of a single set of equation-of-state-generated size parameters over the temperature range of 25 to $60{ }^{\circ} \mathrm{C}$ with temperature-dependent interaction parameter. The root-meansquares (RMS) errors of the calculated VLE values along with the number of data points used are also presented in Tables $\mathbf{2}$ and $\mathbf{3}$ for each of the systems considered. These values may be used as a guide to assess the quality of the experimental data when more than one set of data were measured at the same temperature or pressure condition for the same mixture but the RMS errors were quite different. It is also remarkable that the VLE data reported by Byer et al. [44] and Van Ness and Abbott [45] for the chloroformtetrahydrofuran system at $30{ }^{\circ} \mathrm{C}$ can be accurately represented by the reformulated van Laar equation with a single adjustable parameter.

The capability of the reformulated van Laar equations in representing the VLE values of multicomponent mixtures was tested by using the parameters determined from the experimental VLE data for the constituent binary mixtures to predict the bubble-point pressures and bubble-point temperatures of the $\{$ n-hexane + cyclohexane + benzene $\}$ system. The predicted values were then compared with the experimental values reported by Li et al. [50] and those by Ridgway and Butler [18], respectively. As shown in Figs. (20 and 21), respectively, the predicted values agree very well with the experimental values. In particular, the RMS deviation of the predicted bubble-point temperatures was $0.19{ }^{\circ} \mathrm{C}$ and that of the predicted bubble-point pressures was $0.032 \mathrm{kPa}$. The corresponding RMS errors of the vapor compositions were $0.0060,0.0062$ and 0.0046 for the bubble-point temperature predictions and $0.0041,0.0076$, and 0.0062 for the bubblepoint pressure predictions. Similar calculations were also made to compare the predicted VLE values with the experimental results reported by Katayama et al. [40] and Myers

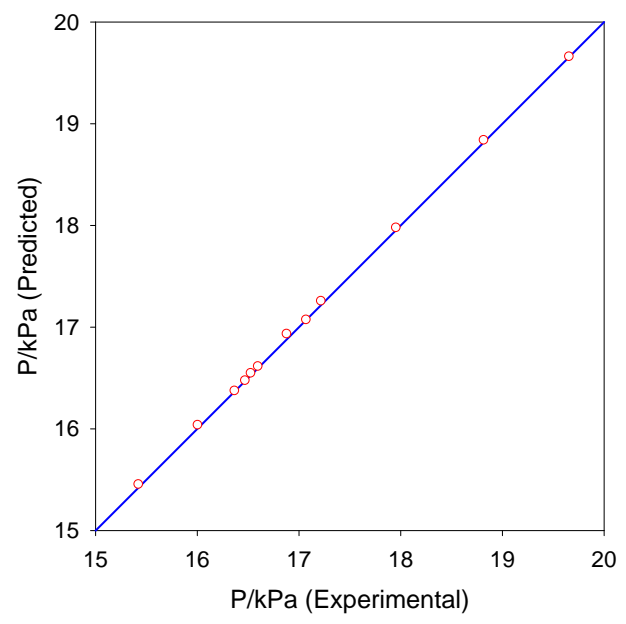

Fig. (20). Comparison of the predicted bubble-point pressure with the experimental values reported by $\mathrm{Li}$ et al., [50] for the $\{n$-hexane + cyclohexane + benzene $\}$ system at $298.15 \mathrm{~K}$.

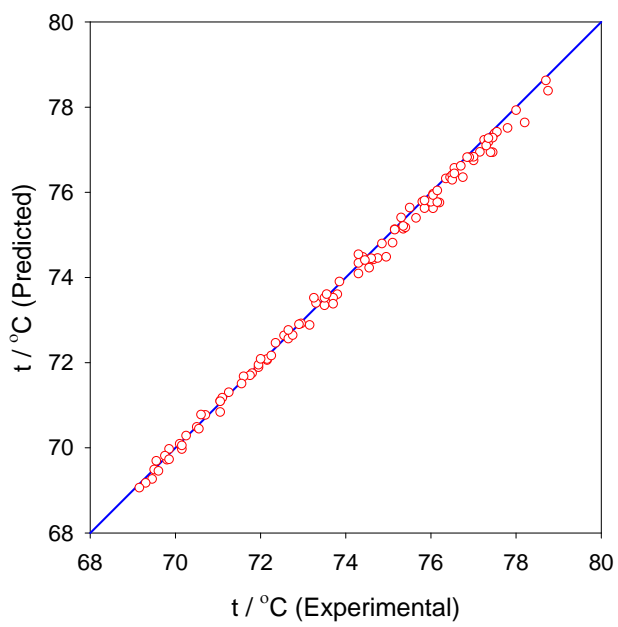

Fig. (21). Comparison of the predicted bubble-point temperature with the experimental values reported by Ridgway and Butler [18] for the $\{n$-hexane + cyclohexane + benzene $\}$ system at $101.33 \mathrm{kPa}$.

[51] for the $\{n$-heptane + cyclohexane + toluene $\}$ system. The comparisons are shown in Figs. (22 and 23), respectively. The RMS errors were $0.17 \mathrm{kPa}$ and $0.37{ }^{\circ} \mathrm{C}$, respectively. The corresponding RMS errors of the predicted vapor compositions were $0.0059,0.0081$, and 0.0086 for the bubble-point pressure predictions and $0.0042,0.0068$, and 0.0049 for the bubble-point temperature predictions. These comparisons serve to show that the reformulated van Laar equations can be used with the information obtained from the constituent binary systems to predict with very good accuracy the behavior of multicomponent hydrocarbon systems.

The reformulated van Laar equations were tested for its capability to predict the VLE values of multicomponent systems involving non-hydrocarbons or polar fluids. The size parameters calculated from the critical constants were used to represent the hydrocarbon components. However, the parameters calculated in the same manner did not always represent the polar components as well as they did the binary systems of water-methanol and chloroform-tetrahydrofuran. Thus, to predict the VLE values of polar-componentcontaining multicomponent systems, one would have to de- 


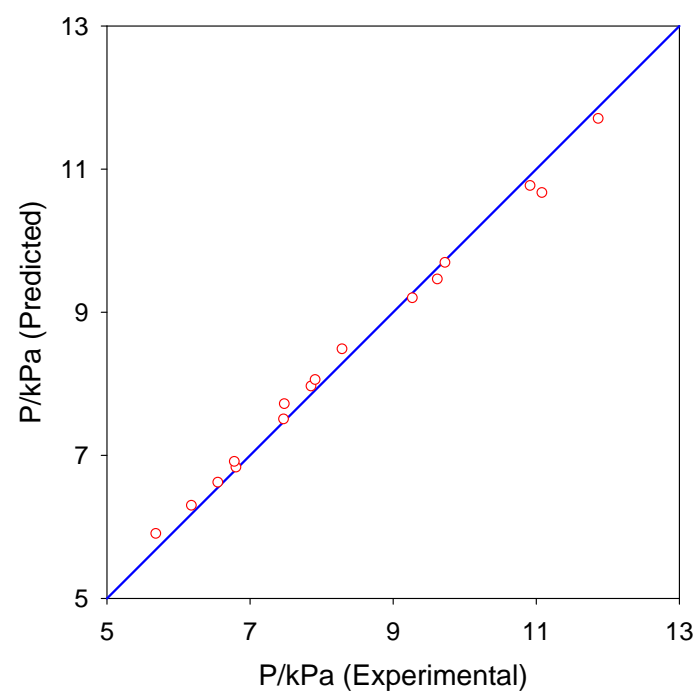

Fig. (22). Comparison of the predicted bubble-point pressure with the experimental values reported by Katayama et al., [40] for the $\{n$-heptane + cyclohexane + toluene $\}$ system at $298.15 \mathrm{~K}$.

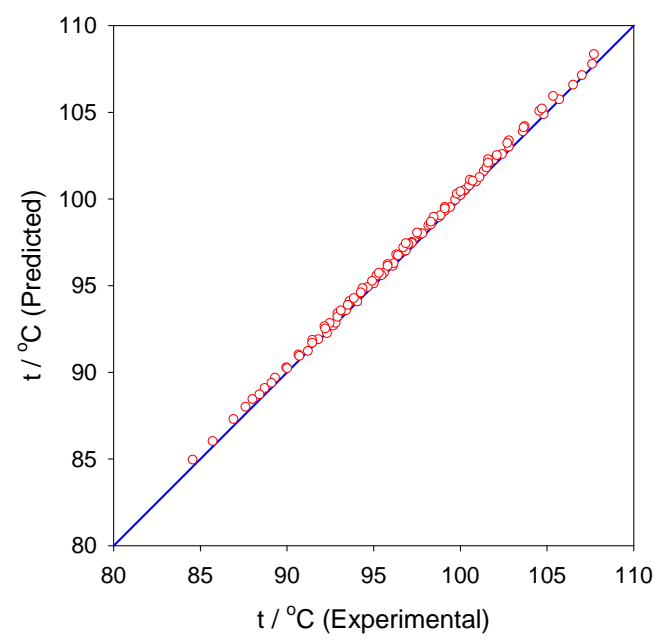

Fig. (23). Comparison of the predicted bubble-point temperature with the experimental values reported by Myers [51] for the $\{n$ heptane + cyclohexane + toluene system at $101.33 \mathrm{kPa}$.

termine the optimal size parameters for the non-hydrocarbon components and the binary interaction parameters by regression on the VLE data of all constituent binary systems. A more extensive account of the application of the reformulated van Laar equations to multicomponent mixtures involving one or more polar components is in preparation and will be presented in a forthcoming paper

\section{CONCLUSIONS}

The original van Laar equation for the excess Gibbs free energy of mixing has been rectified by taking into consideration the temperature-dependency of the energy parameter in modern cubic equations of state. A simplified expression has been obtained by grouping all terms involving the energy parameters into a single parameter to characterize the interaction between two different molecules in a mixture. The reformulated van Laar equation has been successfully applied to multicomponent hydrocarbon mixtures as well as mixtures involving non-hydrocarbons. For the hydrocarbon systems, the size parameters can be accurately calculated by means of the critical constants of the constituent components and the correlation of the VLE data of a binary hydrocarbon system is reduced to a simple one-parameter searching process.

\section{ACKNOWLEDGEMENT}

The financial support provided by the Natural Sciences and Engineering Research Council of Canada is gratefully acknowledged.

\section{NOMENCLATURE}
$\mathrm{A}, \mathrm{B}=$ Dimensionless parameters in the Carlson- Colburn forms of the van Laar equations
$a=$ Energy parameter in Equation (13)
$b=$ Size parameter in Equation (13)
$\mathrm{C}=$ Dimensionless constant defined in Equation (16)
$\mathrm{G}=$ Molar Gibbs free energy
$\mathrm{H} \quad=$ Molar enthalpy
$\mathrm{R}=$ Universal gas constant
$\mathrm{P} \quad=$ Pressure
$r \quad=$ Dimensionless parameter defined in Equation
$\mathrm{p} \quad=$ Partial pressure (6)
$\mathrm{T}=$ Absolute temperature
$u, w=$ Constants in Equation (13)
$x=$ Mole fraction of component in the liquid phase
$y=$ Mole fraction of component in the vapor phase
$\hat{a}=$ Dimensionless parameter defined in Equation (7)
$\gamma=$ Activity coefficient
$\varepsilon=$ Interaction parameter

\section{Superscripts}

$\mathrm{E} \quad=$ Excess property

$\circ \quad=$ Pure state

\section{Subscripts}

c $\quad=$ Critical property

$\mathrm{i}, \mathrm{j}, \mathrm{k}=$ Component indices

$1,2,3=$ Component indices

\section{REFERENCES}

[1] M. Margules, "Über die Zusammensetzung der gesättigten Dämpfe von Mischungen", Sitzungsber Akad. Wiss. Wien, Math. Naturw. Klasse, II, vol. 104, pp. 1243-1278, 1895.

[2] J. J. van Laar, Sechs Vorträgen über das thermodynamische Potential. (Six Lectures on the Thermodynamic Potential). Braunschweig, Fried. Vieweg \& Sohn, 1906.

[3] J. J. van Laar, "Über Dampfspannungen von binären Gemischen (The vapor pressure of binary mixtures)", Z. Physik. Chem., vol. 72, pp. 723-751, May 1910.

[4] J. J. van Laar, "Zur Theorie der Dampfspannungen von binären Gemischen. Erwiderung an Herrn F. Dolezalek (Theory of vapor pressure of binary mixtures. Reply to Mr. F. Dolezalek)", Z. Physik. Chem., vol. 83, pp. 599-608, June 1913. 
[5] G. M. Wilson, "Vapor-liquid equilibrium. XI. A new expression for the excess free energy of mixing", J. Am. Chem. Soc., vol. 86, pp.127-130, January 1964.

[6] H. Renon and J. M. Prausnitz, "Local compositions in thermodynamic excess functions for liquid mixtures", AIChE J., vol. 14, pp. 135-144, January 1968.

[7] D. S. Abrams and J. M. Prausnitz, "Statistical thermodynamics of liquid mixtures: A new expression for the excess Gibbs energy of partly or completely miscible systems", AIChE J., vol. 21, pp. 116128, January 1975.

[8] J. Gmehling and U. Onken, Vapor-liquid Equilibrium Data Collection. DECHEMA, Franckfurt/Main, 1977.

[9] R. R. White, "Vapor-liquid equilibria in nonideal solutions", Trans. Am. Inst. Chem. Engrs., vol. 41, pp. 539-554, February 1945.

[10] K. Wohl, "Thermodynamic evaluation of binary and ternary liquid systems", Trans. Am. Inst. Chem. Engrs., vol. 42, pp. 215-249, October 1946 and Chem. Eng. Prog., vol. 49, pp. 218-219, April 1953.

[11] C. Black, "Phase equilibria in binary and multicomponent systems", Ind. Eng. Chem., vol. 50, pp. 403-412, March 1958.

[12] H. H. Y. Chien and H. R. Null, "Generalized multicomponent equation for activity coefficient calculation", AIChE J., vol. 18, pp.1177-1183, November1972.

[13] H. C. Carlson and A. P. Colburn, "Vapor-liquid equilibria of nonideal solutions. Utilization of theoretical methods to extend data", Ind. Eng. Chem., vol. 34, pp.581-589, May 1942.

[14] R. Stryjek and J. H. Vera, "An improved Peng-Robinson equation of state for pure compounds and mixtyres', Can. J. Chem. Eng., vol 64, pp. 323-333, April 1986.

[15] P. Proust and J. H. Vera, "PRSV: The Stryjek-Vera modification of the Peng-Robinson equation of state. Parameters for other pure compounds of industrial interest", Can. J. Chem. Eng., vol. 67, pp. 170-173, February 1989.

[16] D.-Y. Peng and D. B. Robinson, "A new two-constant equation of state", Ind. Eng. Chem. Fundam., vol. 15, pp. 59-64, February 1976.

[17] J. A. Barker, "Determination of activity coefficients from total pressure measurements", Aust. J. Chem., vol. 6, pp. 207-210, August 1953.

[18] K. Ridgway and P. A. Butler, "Some physical properties of the ternary system benzene-cyclohexane-n-hexane", J. Chem. Eng. Data, vol. 12, pp. 509-515, October 1967.

[19] P. S. Prabhu and M. Van Winkle, "Effect of polar components on the relative volatility of the binary system n-hexane-benzene", $J$. Chem. Eng. Data, vol. 8, pp. 210-214, April 1963.

[20] R. L. Nielsen and J. H. Weber, "Vapor-liquid equilibria at subatmospheric pressures. Binary and ternary systems containing ethyl alcohol, benzene, and n-heptane", J. Chem. Eng. Data, vol. 4, pp. 145-151, April 1959.

[21] A. R. Richards and E. Hargreaves, "Vapor-liquid equilibria of close-boiling binary hydrocarbon mixtures", Ind. Eng. Chem., vol. 36, pp. 805-808, September 1944.

[22] L. Sieg, "Vapor-liquid equilibria in binary systems of hydrocarbons of various types", Chem.-Ing.-Tech., vol. 22, pp. 322-326, August 1950.

[23] H. S. Myers, "V-L equilibrium for naphthenes and paraffins", Petroleum Refiner, vol. 36, pp. 175-178, March 1957.

[24] J. Cholinski, M. Palczewska-Tulinska, A. Szafranska, and D. Wyrzykowskastankiewicz, "A new method of parameter adjustment and diagnostic checks on gamma models use in vapor-liquid equilibrium calculations", Chem. Eng. Sci., vol. 36, pp. 173-181, January 1981.

[25] S. Yerazunis, J. D. Plowright, F. M. Smola, "Vapor-liquid equilibrium determination by a new apparatus", AIChE J., vol. 10, pp. 660-665, September 1964.

[26] W. W. Bowden, J. C. Staton, and B. D. Smith, "Vapor-liquid-liquid equilibrium of the $n$-pentane-sulfur dioxide-benzene system at 0 ${ }^{\circ} \mathrm{F}$, , J. Chem. Eng. Data, vol. 11, pp. 296-303, July 1966.

[27] J. L.-H. Wang and B. C.-Y. Lu, "Vapour-liquid equilibrium data for the $n$-pentane-benzene system", J. Appl. Chem. Biotechnol., vol. 21, pp. 297-299, October 1971

[28] K. R. Harris and P. J. Dunlop, "Vapour pressures and excess Gibbs energies of mixtures of benzene with chlorobenzene, $n$-hexane, and $n$-heptane at $25^{\circ} \mathrm{C} "$, J. Chem. Thermodyn., vol. 2, pp.805-811, November 1970.
[29] R. S. Murray and M. L. Martin, "A continous-dilution device for the measurement of static vapour pressures of binary liquid mixtures", J. Chem. Thermodyn., vol. 7, pp. 839-846, September 1975.

[30] D. A. Palmer and B. D. Smith, "Thermodynamic excess property measurements for acetonitrile-benzene-n-heptane system at $45^{\circ} \mathrm{C}$ ", J. Chem. Eng. Data, vol. 17, pp. 71-76, January 1972.

[31] I. Brown and A. H. Ewald, "Liquid-vapour equilibria. II. The system benzene-n-heptane", Aust. J. Sci. Res. (A), vol. 4, pp. 198-212, March 1951.

[32] J. Fu and B. C.-Y. Lu, "Binary vapour-liquid equilibria", J. Appl. Chem., vol. 16, pp. 324-326, November 1966.

[33] I. M. Elshayal and B. C.-Y. Lu, "Isothermal vapour-liquid equilibria for the binary system benzene-n-octane", J. Appl. Chem., vol. 18, pp. 277-280, September 1968.

[34] K. Aim, "Measurement of vapor-liquid equilibrium in systems with components of very different volatility by the total pressure static method", Fluid Phase Equilib., vol. 2, pp. 119-142, October 1978.

[35] A. Tasic, B. Djorfjevic, D. Grozdanic, N. Afgan, and D. Malic, "Vapour-liquid equilibria of the systems acetone-benzene, benzene-cyclohexane and acetone-cyclohexane at $25{ }^{\circ} \mathrm{C}$ ", Chem. Eng. Sci., vol. 33, February 1978.

[36] G. Scatchard, S. E. Wood, and J. M. Mochel, "Vapor-liquid equilibrium. III. Benzene-cyclohexane-mixtures", J. Phys. Chem., vol. 43, pp. 119-130, January 1939.

[37] M. Inoue, K. Azumi, and N. Suzuki, "A new vapor pressure assembly for static vapor-liquid equilibrium", Ind. Eng. Chem. Fundam., vol. 14, pp. 312-314, November 1975.

[38] D. Dixon and F. A. Hewitt, "Excess Gibbs function for a binary mixture obtained from dew point and bubble point pressure measurements", J. Chem. Soc., Faraday Trans. 1, vol. 75, pp. 19401949, 1979.

[39] M. L. Martin and J. C. Youings, "Vapour pressures and excess Gibbs free energies of cyclohexane+n-hexane, +n-heptane and +noctane at 298.15 K", Aust. J. Chem., vol. 33, pp. 2133-2138, October 1980.

[40] T. Katayama, E. K. Sung, and E. N. Lightfoot, "Isothermal activity coefficients for the system cyclohexane- $n$-heptane-toluene at 25 ${ }^{\circ}$ C", AIChE J., vol. 11, pp. 924-929, September 1965.

[41] N. Asmanova and M. Goral, "Vapor pressures and excess Gibbs energies in binary mixtures of hydrocarbons at $313.15 \mathrm{~K}$. 1. Methylcyclohexane-benzene, -toluene, -o-xylene, -p-xylene, ethylbenzene, and -propylbenzene", J. Chem. Eng. Data, vol. 25, pp. 159-161, April 1980.

[42] M. Diaz-Pena, A. Crespo-Colin, and A. Compostizo, "Gibbs excess free energy of methylcyclohexane + benzene and methylcyclohexane + toluene mixtures at 348.15 K", J. Chem. Eng. Data, vol. 28, pp. 30-33, January 1983.

[43] I. Wichterle and L. Boublikova, "Semimicromethod for determination of partial pressures of solutions", Ind. Eng. Chem. Fundam., vol. 8, pp. 585-588, August 1969.

[44] S. M. Byer, R. E. Gibbs, and H. C. Van Ness, "Vapor-liquid equilibrium: Part II. Correlations from P-x data for 15 systems", AIChE J., vol. 19, pp. 245-251, March 1973.

[45] H. C. Van Ness and M. M. Abbott, "Liquid-vapor equilibrium of the chloroform- tetrahydrofuran system", Int. DATA Series, Selected Data on Mixtures, Ser. A, vol. 1976, no. 2, pp. 118-119, January 1978.

[46] Z. S. Kooner, R. C. Phutela, and D. V. Fenby, "Determination of the equilibrium constants of water-methanol deuterium exchange reactions from vapour pressure measurements", Aust. J. Chem., vol. 33, pp. 9-13, January 1980.

[47] M. L. McGlashan and A. G. Williamson, "Isothermal liquid vapor equilibria for system methanol-water", J. Chem. Eng. Data, vol. 21, pp. 196-199, April 1976.

[48] G. A. Ratcliff and K. C. Chao, "Prediction of thermodynamic properties of polar mixtures by a group solution model", Can. J. Chem. Eng., vol. 47, pp. 148-153, April 1969.

[49] K. Kurihara, T. Minoura, K. Takeda, and K. Kojima, "Isothermal vapor-liquid equilibria for methanol + ethanol + water, methanol + water, and ethanol + water", J. Chem. Eng. Data, vol. 40, pp. 679684, May 1995. 
[50] I. P.-C. Li, J. Polak, and B. C.-Y. Lu, "Ternary vapor-liquid equilibria for $n$-hexane + cyclohexane + benzene", J. Chem. Thermodynamics, vol. 5, pp. 417-424, May 1974.
[51] H. S. Myers, "Vapor-liquid-equilibrium data for the ternary system cyclohexane-heptane-toluene", AIChE J., vol. 3, pp. 467-472, December 1957.

(C) Ding-Yu Peng; Licensee Bentham Open.

This is an open access article licensed under the terms of the Creative Commons Attribution Non-Commercial License (http://creativecommons.org/licenses/by-nc/3.0/) which permits unrestricted, non-commercial use, distribution and reproduction in any medium, provided the work is properly cited. 